\title{
EXPERT TESTIMONY: ITS ABUSES AND USES.*
}

Judge Endlich, of the Courts of Berks County, Pennsylvania, in an able address before the Pennsylvania Bar Association in July, I898, reverts to the fact that in "England, New York, Màssachusetts, this State, and elsewhere the subject of a change" (in expert evidence) "is undergoing discussion and agitation." $\mathrm{He}$ adds, "In the appendix to 'Rogers on Expert Testimony' are collected twenty-five judicial expressions of opinion, concerning the value of such testimony, taken from the reports of England, of United States Courts, and various State Courts of last resort. Seventeen declare it to be of little value, and only eight have a good word to say for it. Recent decisions appear to be even more generally agreed in depreciating it, and the same is to be said of legal text-books and journals." Furthermore, "It is a deplorable fact, patent to any one who chooses to inform himself, that expert testimony as now received in our Courts is looked upon by the public as an unmitigated farce and a nuisance, etc. ${ }^{1}$ (The italics are the present writer's.)

This presentment by an acknowledged leader in jurisprudence, and highly honored member of the judiciary indicates a very serious state of affairs. Defects in the machinery for the administration of justice menace the very foundations of social order, and should be remedied at once at all hazards. The first inquiry is naturally, "What are experts?" and the second, "What have they to do with.litigation?" It may seem easy to answer the first question until you try.

The writer made several attempts, at the invitation of Judge Endlich, to construct a definition which should satisfy

*This article supplements an article by the same authority which appeared in The American - LAW Register, Vol. 37 N. S., p. 735, December, 1898 .-ED.

"Proposed Changes in the Law of Expert Testimony" by Hon. Gustav A. Endlich. Report of the fourth annual meeting of the Pennsylvania Bar Association, held at the Water Gap, July 7 and 8, 1898. 
both scientific and legal minds, but without entire success. The difficulty lies in the fact that the legal mind adheres to the guinea's stamp as a criterion of value in preference to a determination of the real nature of the metal on which it is impressed; while he who is not of the law regards the quality of the metal as more important than the stamp. This difference is not easy to adjust because it is rooted in common law, and in the conceptions of a function of a jury. The second attempt of the writer to produce a. satisfactory - definition and the criticism it evoked will illustrate this: "An expert is one who by greater power of discernment than ordinary men [either as a gift of nature or] by reason of a greater number of previous experiences, is better able than they to elucidate a given question."

Two leaders of the Pennsylvania Bar were consulted. Mr. John G. Johnson, replied that the greater power of discernment was superfluous. If the expert has had a sufficient number of previous experiences he will-be admitted. Mr. Samuel Dickson defined an expert"as "one having such special knowledge as to make his opinion a reasonable ground of belief."

The thought underlying the above criticism and definition is that the court does not feel called upon to ascertain the reality of his special knowledge before accepting the expert, and hence his appointment must be based simply upon his having enjoyed opportunities to become qualified, whether or not he profited by them; or upon his success in imposing on some other court previously as to his history or reputation. Both these gentlemen as well as Judge 'Endlich himself (who would allow inferences to one who has "pursued the study or had the experience") express, or imply that the sole admissibility test of an expert is the opportunities he may have had to become one. To the layman it seems better that the form in which the expert is required to give his testimony should, itself, furnish proof of his fitness. This the writer sought to accomplish in the draft of a law governing expert testimony in handwriting, which is now one of the statutes of Pennsylvania, by requiring the expert to give first, the principles governing his procedure; second, the facts which he obtained; third, the conclusions he draws from 
those facts. Such a statement would expose the expert to complete annihilation at the hands of any other expert assisting the cross-examiner, unless principles, procedure, and conclusions were sound. But it is objected by lawyers to this principle that it removes from the jury its right to take ratiocinative steps and reach conclusions as, by the common law, it alone is authorized to do. The inconsistency of this objection is apparent if we suppose a. jury called upon to decide whether a certain yacht has fulfilled the contract specifications in tonnage, load line, and metacentric, from the measurements which a shipbuilder would furnish. It is still more apparent if we consider that judges and lawyers hold their positions as such solely because of their expert knowledge of law, and, though the statutes provide otherwise, it is just as reasonable to procure for a jury a list of authorities on a point of law and ask it to reach its own opinion of the application in a given case, as to assign that duty exclusively to a judge, be he a Marshall or a Story; because all the judge can do is to reason from these facts to his conclusion. We may assume that from the legal point of view an expert is one who has knowledge from a special study, or unusual experience, enabling him to draw from facts inferences which a jury would not of itself be able to draw.

If a court be "a tribunal established for the administration of justice," the subjects which come before it are as various as the interests of the community in which it exists. These interests at the present day comprise every element in animate and inanimate nature; and every item in Science, Art, Literature, and Religion. To judge fairly between litigants on any of these subjects implies that the jury comprehend the nature of the subject in dispute. Either the court and jury must have supernatural knowledge, extending from electrical measurements to the interpretation of hieroglyphics; or else, when exact knowledge is required on a given subject, some one who has this knowledge must be called upon to supply it. Such person is called an expert, as all will agree. Intricate questions involving medical skill must be decided to determine the cause of death or the extent of injury. Thorough comprehension of the action 
of separate pieces of apparatus must precede a knowledge of whether one of them infringes the patent rights of the other. Chemical reactions of great delicacy must be interpreted to settle controversies as to value, or fulfillment of contract. Extensive experience and intelligent investigation are necessary to demonstrate whether two writings are, or are not, written by the same hand. It is just as clear that special knowledge, needed in the above cases, must come from experts in the several classes as it is clear that the bearing upon them of the law must come from the experts called judges. Indeed, as the, address of Judge Endlich, before the Pennsylvania Bar Association declares, while deploring the outcry against experts, "that expert testimony has been so long tolerated by the courts, including those professing to despise it, and that in spite of everything its uses are on the increase, proves that we cannot do without it, nor ought we to wish to do without it. . . . It is not expert testimony itself, therefore, that is an evil. The evil lies in our way of handling it," etc. Lawyers and laymen will agree that the modest instrument of justice known as an "expert" has value; the difference between them is solely as to the best method of securing experts who really possess this value.

The writer believes that the methods by which expert testimony is obtained and handled are mainly responsible for the evils which are denounced and deplored. For those methods the bar is mainly responsible; through its exclusive control of the legislation affecting procedure in the courts; and through its attitude towards these instruments who, it is conceded, are necessary adjuncts for procuring the facts on which the jury is to decide many cases. From attorneys, whose code is fidelity to the cause of their clients even "though success involve the destruction of the government," it is natural to expect all the arts of insinuation, detraction, and invective, directed against the man whose testimony may lose one of them his case. They are advocates and strong partisans, yet there is a striking difference between them. The most learned and successful practitioners are invariably the most courteous towards their opponent's expert, yet even these do not entirely deprive themselves of the 
advantages which lurk in such questions as: "How much do you expect to be paid for testifying?" "You knew beforecommencing your examination what my learned Brother wished to prove by your testimony, did you not?" "Have you not frequently differed in opinion from other experts, and has not the jury frequently'reached conclusions opposite to yours?" These innuendoes are, strictly speaking, not quite fair, and may bè made, by tone and manner, very galling, but from the lawyer's point of view they are not unprofessional. Far worse and less excusable is the conduct of some judges. Placed temporarily in a position of absolute and arbitrary power; charged with the duty of eliciting, the truth, and incidentally of protecting reputable witnesses from all kinds of insult, occasionally some of them seem to welcome the occasion to offer indignity by word and manner to expert witnesses.

The injustices of trial judges to expert witnesses may either be the result of a misunderstanding of the actual significance of their testimony; or a misunderstanding of previous decisions of Appellate Courts towards similar questions; or they may unjudicially allow their prejudice to escape through contemptuous words; or they may reproach expert witnesses for that which is perfectly legal and proper; or they may misstate the testimony either from inattention, from lack of power of discrimination, or from general ignorance. There are doubtless other ways in which injustice may be done by trial judges to particular experts and harm to expert testimony generally. The present writer cites from his own experience of twenty-two or more years, cases under each of these heads. The following is an example of a misunderstanding of the actual significance of the testimony:

The owners of a valuable coal property brought suit against the lessee for a large sum representing the difference between the number of tons mined, as claimed by the plaintiff on the one hand, and as acknowledged by the defendant on the other. The writer was employed by the former to ascertain the actual facts. This was done by ascertaining the number of cubic yards taken out by the lessee, and the weight of a cubic yard of this coal. This látter determina- 
tion demands only a fair sample of the coal as large as a walnut, a balance to weigh it on, and a glass of water in which to suspend while weighing it. All these details were explained to the court; the number of tons ascertained to have been removed, stated; and the witness was about to step down from the stand, when the judge raised his hand in restraint, while his countenance assumed an aspect of great earnestness. "Stop! One moment," said he. "There is a question which has not been put to this witness which 'I regard as of the greatest importance-in fact, pivotal in the case." A hush of expectancy fell upon the court and his Honor, fixing the witness with a look of inspiration, continued, "Do the processes you have just described exercise any influence upon the commercial value of the coal? Now, the fragments taken to obtain a fair average of the whole coal bed would not together have exceeded the dimensions of a watermelon." On recovering his speech, the witness answered "No," and was allowed to depart.

The second example shows the effect of an evident misunderstanding of the trial judge of a prior decision of the Appellate Court.

On or about I790 a tract of land was purchased by compass survey, and, during the succeeding century, a very valuable plant was erected near one of its boundary lines. Some time in the eighteen hundred and seventies the owner of the neighboring tract brought an ejectment suit against the original owners, on the ground that a survey made in 1845 , and later in 1870 , proved that the buildings and improvements were on the plaintiff's land. The boundaries had been re-established in these years by tracing the compass directions recorded in I790 from the indications of a compass in 1870 . It is known that in a wide region, embracing the tract under consideration, the north point by the compass has been 'moving slowly west of the true astronomical north during the past century, so that its direction has never been exactly the same on two successive years. The writer showed to the court that starting from a stone corner which had been preserved, and allowing for this change, the compass direction of $\mathrm{r} 790$ included within the property the buildings of the company; whereas, owing to the change in the magnetic 
north during the intervening time, the same number of degrees west of north by compass in 1870 left these buildings outside of the tract. In other words if the necessary correction be allowed, the boundary line of 1870 would lie where tradition, and the location of the buildings, indicated it must have lain, viz: on the outer side of these latter. But the judge, after consulting his authorities, announced that the Supreme Court of the state in question once having had presented to it an argument based upon the variation of the magnetic needle, had decided that in the particular case then before it certain facts were established which rendered the consideration of the argument unnecessary. Then, closing the book, he added that this precedent of the Supreme Court would be followed by himself; and thereupon ruled out the testimony regarding the change of direction of the magnetic needle, which was the essence of the whole dispute.

All the rest of the faults above enumerated are found in a written opinion of more recent years which is herewith quoted. (The italics are the writer's.)

"The whole of the libellant's case rests upon the testimony of two alleged experts upon the subject of handwriting who testify that in their opinion the will in question is forged, it will be observed that neither of them testify to any fact but to an opinion which is predicated upon an examination made by one of them of eight letters written by the testator, and by the other of four said letters, and which are admittedly genuine, and a comparison of a signature thereto with that to the will. While both these witnesses admit that no man ever signs his name exactly alike twice, yet they undertake to testify that because there is some slight variation or difference between a signatire to a will in 1899 and that to $a$ letter written in I88I, nearly thenty years previously, and other letters zeritten at more or less remote periods since that, the signature to the will is forged. The genuine appearance and characteristics of all the signatures may be similar, yet because by the aid of a microscope and measurements they can detect a slight variation of size of a signature dozen to an infinitesimal fraction, a difference in the flourish under it, a connection or disconnection between two of the letters, a letter higher up or lower down in one signature 
than the other, and other similar variations which it is impossible to discover with the naked eye they are willing to testify that this will is forged. There were perhaps over a hundred signatures which were undoubtedly made by Mr. put in evidence in this case and in a great many of them the characteristics and peculiarities which these experts point out as a badge of forgery exist."

The statement "alleged experts" is an illustration of the use of the contemptuous expressions by judges to which II have referred. The particular expression is illogical because if the judge had not considered the witnesses actually experts he failed in his duty in allowing them to testify as such. Again the emphasis laid by the judge on the fact that the experts testified that "in their opinion" is reproaching them for. testifying in the only way in which the law permits them to testify.

The last part of the opinion quoted illustrates two kinds of misstatement. The assertion that a will is a forgery is a statement of a legal conclusion from a combination of facts. For an expert in handwriting to testify that a will is a forgery is improper. The writer who as intimated was one of the witnesses, did not testify that the will was a forgery. He never testified thus about any signature, holding that the question of forgery is partly a question of law. In this particular case he had no such opinion. He was and is still firmly of the opinion that the signature was not by the hand of the man it designated. Need it be stated that that is a vastly different thing? The above is an illustration of misstatement of that to which the expert testified, but the opinion also contains an illustration of the way in which a trial judge may misunderstand and therefore misstate the reasons which induced the expert tö reach his conclusions. These conclusions, in the particular case referred to, were reached, not because of "some slight variation or difference between the signature to the will," and other "admittedly genuine signatures," but because of a number of such superficial differences (each one trifling in itself but all together constituting an indication of some significance), were confirmed by several inherent and involuntary characteristics which in the opinion of the witness could neither be simulated 
nor suppressed. The judge confused the superficial and non-essential with the essential characteristics. It is true that though two signatures may be alike to the eye, by an examination under the microscope, their difference or origin may be manifest through differences of structure which belong to the domain of the "infinitesimal," $i$. e., hundreths of an inch. The character of the flourish-of the position of letters with reference to each other, etc., in spite of the judge's assertion to the contrary, are coarse peculiarities which appeal to the naked eye and when by themselves are of little weight, but cumulatively may be of some value, and sometimes of great value, in reaching a conclusion. The statement that many of the admitted signatures contained the characteristics which one of the witnesses found to distinguish the disputed signature is very extraordinary and reckless. If it were true, which is extremely improbable, the fact could not possibly be known to the person who states it because such signatures were never examined in a manner which would permit this fact to be ascertained.

Perhaps the last example given is an extreme one. What concerns us here is the effect of the attitude of the bench indicated upon the class of expert witnesses. Nothing is truer than that every act of consideration and respect towards an individual or a class makes that individual or class more anxious to deserve and actually more deserving of respect. While every indignity it is made to suffer without possible redress, degrades it to a like extent, and if discourtesy and misrepresentation from the bench become common, no selfrespecting man will put himself in the way of incurring it. It is the belief of the writer that a more general extension of the amenities to expert witnesses which a majority of judges now accord, would go far towards solving the much discussed expert problem.

The writer would also suggest that the character of the expert's testimony may be raised to a judicial standard by requiring the testimony to be introduced in a manner that will result in exposing false or trivial statements. One such method is found in the present act of the State of Pennsylvania above referred to. It is as follows: (The italics are the present writer's.) 
"It shall be competent for experts in giving their testimony under the provisions of this Act, to make comparison of documents and comparison of disputed handwriting with any documents or writing admitted to be genuine, or proven to the satisfaction of the judge to be-genuine, and the evidence of such experts respecting the same shall be submitted to the jury as evidence of the genuineness or otherwise of the writing in dispute.

"It shall be competent for experts in formulating $\dot{r}$ :Iopinions to the court and jury to place the genuine and disputed signatures or writings in juxtaposition, and to draw the attention of the jury thereto; and it shall furthermore be competent for counsel to require of an expert $a$ statement of the principles on which he has based his work, the details of his work, and his opinion that the results are important to the point at issue, or the reasoning, analysis and investigation by which he has arrived at his opinion. ${ }^{2}$

This 'act virtually provides a test of competency of the most rigorous kind. Only one suffering from such feebleness of mind as would preclude his appearance as an expert on general grounds would dare to incur the risk of reciting on the witness stand as the basis of his opinion, procedures and reasonings on their results which were untrue or inapplicable.

February, I902.

Persifor Frazer.

` 189,5, May' I5; P. L. 69 , \$\$ 2 and 3. 